\title{
Clinical Presentation, Diagnosis, and Bacterial Epidemiology of Peritoneal Tuberculosis in Two University Hospitals in France
}

\author{
Zoé Cavalli · Florence Ader · Florent Valour · Julien Saison • \\ Loïc Boussel · Oana Dumitrescu · Thomas Perpoint · Christian Chidiac · \\ Thierry May $\cdot$ Tristan Ferry $\cdot$ Lyon TB Study group
}

Received: April 23, 2016/ Published online: June 13, 2016

(C) The Author(s) 2016. This article is published with open access at Springerlink.com

\begin{abstract}
Introduction: Diagnosis of peritoneal tuberculosis (pTB) is difficult, even in developed countries, where data are lacking. The aim of the present study was to describe the clinical presentation, diagnosis, and bacterial epidemiology of pTB in France over a 10-year period.
\end{abstract}

Methods: A retrospective study was conducted on pTB in two university hospitals in France, between January 2004 and December 2014.

On behalf of the Lyon TB Study group.

Enhanced content To view enhanced content for this article go to http://www.medengine.com/Redeem/ C6D4F0603D2C3510.

Z. Cavalli $(\bowtie) \cdot$ F. Ader · F. Valour · J. Saison ·

T. Perpoint - C. Chidiac . T. Ferry

Service de Maladies Infectieuses et Tropicales, Hôpital

de la Croix-Rousse, Hospices Civils de Lyon, Lyon,

France

e-mail: zoe.cavalli@chu-lyon.fr

Z. Cavalli · F. Ader · F. Valour · J. Saison · L. Boussel ·

O. Dumitrescu · T. Perpoint · C. Chidiac · T. Ferry

Université Claude Bernard 1, Lyon, France

F. Ader · F. Valour · C. Chidiac · T. Ferry

Centre Internationale de Recherche en

Infectiologie, CIRI, Inserm U1111, CNRS UMR5308,

ENS de Lyon, UCBL1, Lyon, France
Results: Among the 34 patients, 76.5\% were migrants from areas of endemic tuberculosis (TB), mainly Africa. The main presentation $(85.3 \%)$ was a checkup of ascites or suspicion of peritoneal carcinomatosis. On abdominal computed tomography, ascites was found in $90.6 \%$ and peritoneal thickening in $75 \%$. Surgery was required for diagnosis in $58.8 \%$ of patients. Six of the patients who did not undergo surgery had ultrasound-guided peritoneal biopsy. Bacteriology was positive for ascites in only $58.1 \%$ of cases, for peritoneal biopsy in $73.3 \%$, while granuloma was found in 95.5\%. TB polymerase chain reaction (PCR) was positive in $25 \%$ of peritoneal biopsy.

\footnotetext{
L. Boussel

Service de Radiologie, Hôpital de la Croix-Rousse, Hospices Civils de Lyon, Lyon, France

O. Dumitrescu

Laboratoire de Bactériologie, Hôpital de Lyon Sud, Hospices Civils de Lyon, Lyon, France

T. May

Service de Maladies Infectieuses et Tropicales, Hôpital de Brabois, CHU de Nancy,

Vandœuvre-lès-Nancy, France

T. May

Université de Lorraine, Nancy, France
} 
Mycobacterium bovis was isolated in $23.1 \%$ of cases and Mycobacterium tuberculosis in $76.9 \%$. Isolates were fully susceptible (except M. bovis naturally resistant to pyrazinamide). Many (38\%) belonged to the lineage $\mathrm{T}$ (genetic analysis by spoligotyping). Cure rate was high (76.5\%), after a 6-9 months of anti-tuberculous therapy.

Conclusion: In developed countries, early diagnosis of pTB is still a challenge. Ultrasound-guided peritoneal biopsy may facilitate diagnosis. TB PCR can be useful on peritoneal biopsy. The lineage $\mathrm{T}$ was the most prevalent lineage, but more data are required to directly incriminate this lineage in the pathophysiology of pTB.

Keywords: Ascites; Mycobacterium tuberculosis; Peritoneal biopsy; Peritoneal tuberculosis; Spoligotyping; Tuberculous peritonitis

\section{INTRODUCTION}

Despite the better control of tuberculosis (TB) in the world, the proportion of extrapulmonary TB has increased in recent years [1]. In this context, peritoneal $\mathrm{TB}$ (pTB) represents the most frequent form of abdominal TB [2]. Data are lacking in developed countries since most studies were done in endemic countries of TB [2-4]. The aim of the present study was to describe the clinical presentation, diagnosis, bacterial epidemiology, treatment, and outcome of pTB in two university hospitals in France over a 10-year period.

\section{METHODS}

All patients diagnosed with pTB in the university hospitals of Lyon (Croix-Rousse Hospital) and Nancy (Brabois Hospital) between January 2004 and December 2014 were included in a retrospective observational study. France is a country with an incidence of 8.7 per 100,000 population (including $27 \%$ of extrapulmonary) [5] and the two cities Lyon and Nancy count 1.3 million and 300,000 people, respectively. Patients were identified by using the database of the administrative coding system (patients with diagnosis of pTB in the infectious disease unit) and the database of the mycobacteriological laboratory of Lyon and Nancy (patients with a positive culture or polymerase chain reaction [PCR] of ascites or peritoneum). Children and patients with peritonitis due to non-tuberculous mycobacteria were excluded. Patients without culture or PCR confirmation of TB but with peritonitis consistent with pTB based on clinical, radiographic or histologic evidence were included. Clinical, imaging and bacteriological data were collected. Ascites samples were processed in biosafety level 3 facility as follows: briefly samples were centrifuged for $15 \mathrm{~min}$ before inoculation to solid (Löwenstein-Jensen) and liquid (MGIT-Bactec) media. Pellets were heat inactivated and then used for acid fast bacilli smear test with fluorescent microscope. Heat-inactivated samples were further processed for DNA extraction with MagNA Pure Roche System and then used for Mycobacterium tuberculosis specific in house PCR reaction. Cultured strains were characterized by spoligotyping (spacer oligonucleotide typing), a PCR-based method for genotyping strains [6] and categorized by lineage, using the SpolDB4 database [7]. Statistical methods used were medians and percentages.

The study has been approved by the institutional ethics committee. All procedures followed were in accordance with the ethical 
standards of the responsible committee on human experimentation (institutional and national) and with the Helsinki Declaration of 1964, as revised in 2013. Informed consent waiver was granted as all data were currently in existence.

\section{RESULTS}

Thirty-four patients were included (29 in Lyon and 5 in Nancy). There was male predominance, with 22 men and 12 women; median age was 40 years. Twenty-six patients (76.5\%) were migrants from areas of endemic $\mathrm{TB}$, mainly Africa. One or more underlying disease was found in 13 patients (38.2\%): liver cirrhosis (6), diabetes mellitus (6), chronic viral hepatitis (4) or immunodepression as cancer (4), immunosuppressive therapy (3) and human immunodeficiency virus (1, who was already treated and controlled). HIV was tested for $32 / 34$ patients $(94.1 \%)$. Two patients $(5.9 \%)$ had history of cured TB; history of TB exposure was reported by seven patients $(20.6 \%)$. The main presentation that lead to hospitalization (29 patients: $85.3 \%$ ) was a checkup of ascites or

Table 1 Symptoms and signs at the presentation $(N=34)$

\begin{tabular}{ll}
\hline Symptoms & $\boldsymbol{n}(\%)$ \\
\hline Fever and/or sweats & $24(70.6 \%)$ \\
Abdominal pain & $24(70.6 \%)$ \\
Ascites or abdominal swelling & $19(55.9 \%)$ \\
Weight loss & $16(47.1 \%)$ \\
Asthenia & $11(32.4 \%)$ \\
Diarrhea & $4(11.8 \%)$ \\
Anorexia & $3(8.8 \%)$ \\
Abdominal mass & $1(2.9 \%)$ \\
Salpingitis & $1(2.9 \%)$ \\
\hline
\end{tabular}

suspicion of peritoneal carcinomatosis; two patients (5.9\%) presented peritonitis. The main symptoms and signs are given in Table 1. Four patients (11.8\%) presented acute abdominal illness requiring emergency laparotomy (two initially and two secondarily). Median symptom duration before admission was 1 month.

Biological findings revealed biological inflammatory syndrome in all patients, with a median C-reactive protein level of $95 \mathrm{mg} / \mathrm{L}$. Lymphopenia (under $1.5 \mathrm{G} / \mathrm{L}$ ) was found in 23 of the 30 patients investigated (76.7\%). Interferon- $\gamma$ release assay (QuantiFERON-TB ${ }^{\circledR}$; Cellestis) was positive in only $16 / 22$ patients (72.7\%), and $15 / 24(62.5 \%)$ had positive (at least $10 \mathrm{~mm}$ ) tuberculin test (Tubertest ${ }^{\circledR}$; Sanofi Pasteur). Ascitic fluid analysis found exudate in $17 / 21$ patients $(80.1 \%)$, with lymphocytic predominance in $19 / 21$ cases $(90.5 \%)$.

On abdominal computed tomography (CT), ascites was found in $29 / 32$ patients $(90.6 \%)$, and was the only abnormality in $4 / 32$ of these (13.8\%). Peritoneal, mesenteric, and/or omentum thickening (Fig. 1) was detected in 24 patients (75\%). Only three patients $(8.9 \%)$

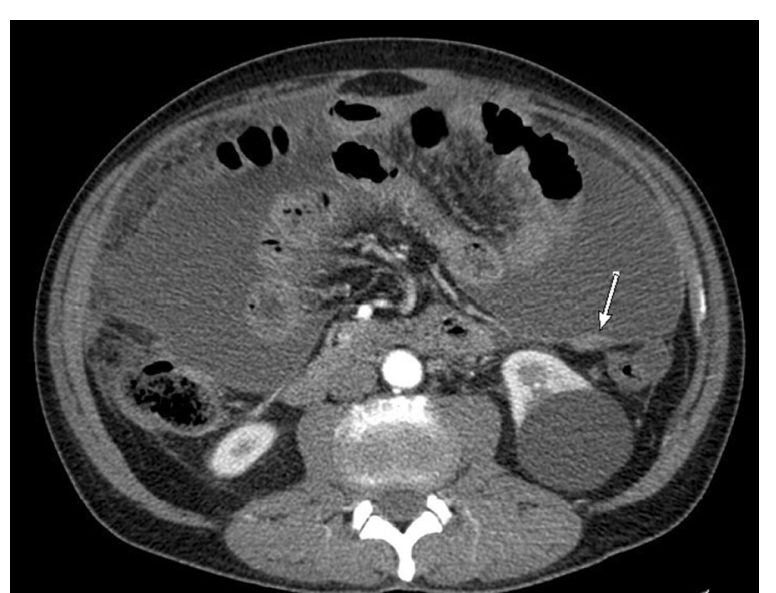

Fig. 1 Abdominal computed tomography of a peritoneal tuberculosis, with peritoneal nodular thickening (white arrow) and ascites 
had no ascites on CT scan, corresponding to the "dry plastic" form of pTB, defined by Bhargava [8]. Abdominal ultrasound was equal to CT to detect ascites $(25 / 28,89.3 \%)$ but less efficient in detecting peritoneal thickening $(6 / 28,21.4 \%)$. Six patients (17.8\%) had positron emission tomography, showing increased peritoneal or mesenteric and lymph node metabolic activity, which could not be differentiated from carcinomatosis. Thirty-two out of 34 thoracic CT (94.1\%) were abnormal with pleural effusion (12), mediastinal lymph node (9), micronodules (8), nodule (4), or excavation (1). Surgery was required for diagnosis in 20 cases $(58.8 \%)$, including 14 laparoscopies (41.2\%) and six laparotomies (17.6\%). Intraoperative visual inspection was suggestive of pTB in 13 patients (65\%), with typical small white peritoneal granulations or granuloma. Six of the patients who did not undergo surgery (42.9\%) had ultrasound-guided peritoneal biopsy. Tuberculous peritonitis was culture-confirmed in 25 patients. Diagnostic performance of the various bacteriological and histological analyses is shown in Table 2. TB PCR, performed on $13 / 31$ ascites samples and on $8 / 14$ peritoneal biopsies, was systematically negative on ascites and positive on only 2 peritoneal biopsies (25\%). It should be noted that a large number of peritoneal biopsies were not sent to the bacteriology laboratory $(8 / 22$, $36.4 \%$ ), because only malignant ascites was suspected by the surgeon. Finally, histological and/or bacteriological diagnostic proof was obtained in all patients, except for three (8.8\%) who did not have peritoneal biopsy but were cured by the anti-TB treatment.

Twenty-six infections were documented. Mycobacterium bovis was isolated in 6 patients (23.1\%) and M.tuberculosis in the others 20 (76.9\%). All isolates were susceptible to classical anti-mycobacterial drugs, except one case of isoniazid resistance (M. bovis is naturally resistant to pyrazinamide). Genetic analysis by spoligotyping, performed in 21 cases, revealed that 8 (38\%) belonged to lineage $\mathrm{T}$ (Table 3). T family lineage is characterized by the absence of spacers 33-36 among the 43 spacers targeted by spoligotyping; the prototypic shared spoligotype is SIT53. There was no specific clinical characteristic for the spoligotype T.

Sixteen patients $(47.1 \%)$ showed one or more other TB location, including lung (five patients), and digestive (four patients), gynecological (four patients) and urological (two patients) tract. Sputum smear examination or bronchoalveolar lavage was performed in 32 patients (94.1\%) and cultures

Table 2 Diagnostic performance of bacteriological and histological analyses in patients with peritoneal tuberculosis

\begin{tabular}{lll}
\hline & Ascites & Peritoneal biopsy \\
\hline Total & 32 & 22 \\
Positive culture & $58.1 \%(18 / 31)$ & $71.4 \%(10 / 14)$ \\
Positive PCR & $0.0 \%(0 / 13)$ & $25.0 \%(2 / 8)$ \\
Total bacteriological performance & $58.1 \%(18 / 31)$ & $73.3 \%(11 / 15)$ \\
Histological performance: epithelioid giant-cell granuloma & & $95.5 \%(21 / 22)$ \\
Including with caseous necrosis & & $36.4 \%(8 / 22)$ \\
\hline
\end{tabular}

PCR polymerase chain reaction 
Table 3 Spoligotyping of the 21 strains responsible for peritoneal tuberculosis

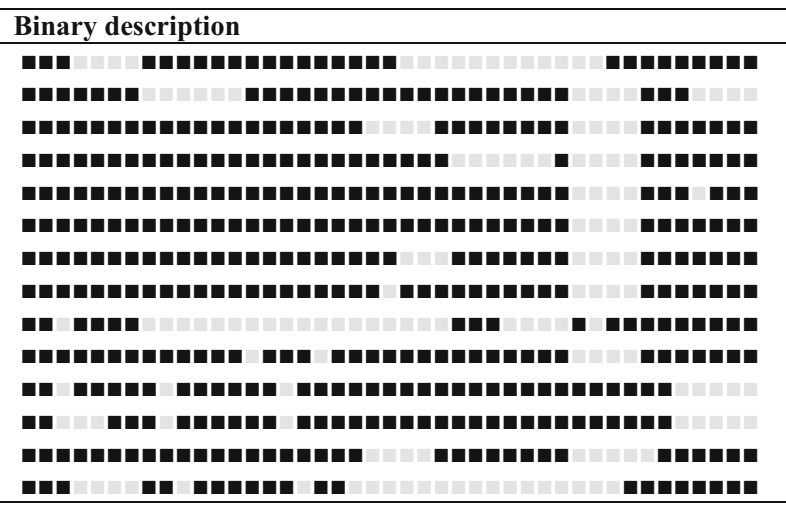

\begin{tabular}{cccc} 
Octal description & SIT & Label & Number of strains \\
\hline 703777740003771 & 26 & CAS1_DELHI & 1 \\
774037777760700 & 31 & T1 & 1 \\
777777607760771 & 42 & LAM9 & 1 \\
777777774020771 & 47 & H1 & 1 \\
777777777760731 & 52 & T2 & 1 \\
777777777760771 & 53 & T1 & 5 \\
777777743760771 & 61 & LAM10_CAM & 1 \\
777777737760771 & 86 & T1 & 1 \\
674000003413771 & 89 & EAI2_NTB & 1 \\
777756777760771 & 302 & X1 & 1 \\
676773777777600 & 482 & BOVIS1_BCG & 3 \\
616773777777600 & 665 & BOVIS1 & 2 \\
777777607760371 & 1070 & U & 1 \\
703375400001771 & $/$ & $/$ & 1
\end{tabular}

SIT Spoligo-International-Type number.

were positive for 5 patients (14.7\%). Extensive surgery with intestinal resection was required in two patients because of digestive perforation; corticosteroids were prescribed for subocclusive syndrome in two patients; and three malnourished patients required artificial nutrition. Median admission-to-treatment time was 18 days. Antimycobacterial therapy comprised standard regimen with daily rifampicin, isoniazid, ethambutol and pyrazinamide during 2 months followed by at least 4 months of rifampicin and isoniazid for 24 patients (70.6\%); the others had therapy without pyrazinamide or without isoniazid and/ or with quinolone because of toxicity or hepatic disorder before treatment. Side-effects led to dose decrease or a change of treatment in 13 patients (38.2\%). Twenty-six patients (76.5\%) completed treatment and were clinically and radiologically cured; four were lost to follow-up; one was still under treatment at the time of writing; and three died during treatment (only one because of disseminated TB). Median treatment duration was 8.5 months, and follow-up without relapse after end of treatment was 12 months.

\section{DISCUSSION}

Early diagnosis of pTB is a challenge as the main presentation of our cohort (85.3\%) was a checkup of ascites or suspicion of peritoneal carcinomatosis. Many different clinical presentations of pTB have been previously described [3]. Due to non-specific and insidious symptoms, there is a significant delay before diagnosis and treatment [4], even in developed countries. Notably, most cases of pTB mimic peritoneal carcinomatosis, especially in women with elevated blood $\mathrm{Ca}$ 125 [9]. In cirrhotic patients, pTB can mimic ascitic decompensation. In addition, imaging findings may point to carcinomatosis [2]. Thus, TB should be systematically considered in case of peritonitis.

Bacteriological performance is imperfect since culture of ascites was positive in only $58.1 \%$ and peritoneal biopsy in $73.3 \%$ of cases. Biopsy for bacterial culture and histology is essential for diagnosis [10]. Histology allows to correct the diagnosis of TB in a large number of cases where bacterial culture was forgotten: it is essential to routinely do mycobacterial culture 
of peritoneal biopsy during an exploration of ascites or peritoneal thickening, unless there is a known intra-abdominal malignancy. Laparoscopic peritoneal biopsy is the reference method for diagnosis of pTB but, as described here, ultrasound-guided biopsy may facilitate diagnosis, with a lower risk of complications [11]. Culture of ascites fluid must be systematic, even if the positivity rate is lower than for peritoneal biopsy, probably because of the low number of bacilli in the processed samples. In the present study, TB PCR seemed to be insensitive when performed on ascites, but can be useful on peritoneal biopsy [12].

Interestingly, we found that a high percentage of isolates responsible for pTB belonged to lineage T. Extrapulmonary TB is usually more frequently associated with the East African-Indian or Central-Asian lineages, whereas lineage $T$, like the Beijing lineage, seems to be more frequently linked to pulmonary forms $[13,14]$. The $\mathrm{T}$ lineage is the predominant lineage in Europe, but not in Africa, where most of our patients have lived before migrating in France [7]. Finally, it is not known if particular lineages are more frequently responsible for $\mathrm{pTB}$ and more data are required to directly incriminate the $\mathrm{T}$ lineage in the pathophysiology of pTB.

In case of suspected pTB, especially with concordant histology, physicians should not wait for culture before initiating treatment, since treatment delay is a very important factor of poor prognosis [4]. The present cure rate was high, and there was no relapse during follow-up.

\section{CONCLUSIONS}

In developed countries, early diagnosis of pTB is still a challenge. Ultrasound-guided peritoneal biopsy may facilitate diagnosis. TB PCR can be useful on peritoneal biopsy. When histology is concordant, prompt treatment initiation may improve prognosis. Data are required to know if particular lineages are responsible for pTB.

\section{ACKNOWLEDGMENTS}

The study was founded by Hospices Civils de Lyon (data collection and performance of spoligotyping). The article processing charges for this publication were funded by EZUS Lyon 1. All named authors meet the International Committee of Medical Journal Editors (ICMJE) criteria for authorship for this manuscript, take responsibility for the integrity of the work as a whole, and have given final approval to the version to be published. We have received substantial contributions from Catherine Laurain, Badis Menassel and the Lyon TB Study group: L. Adelaïde, F. Ader, F. Biron, A. Boibieux, A. Bouaziz, K. Bouledrak, E. Braun, C. Broussolle, G. Carret, G. Catho, N. Charhon, C. Chidiac, W. Chumbi-Flores, B. Coppere, S. Couraud, M. Demontclos, G. Devouassoux, O. Dumitrescu, S. Ernesto, T. Ferry, D. Floret, I. Fredenucci, N. Freymond, S. Gardes, S. Gerbier-Colomban, Y. Gillet, M.H. Girard-Madoux, S. Goutelle, J. Grando, R. Grima, L. Hees, E. Hodille, A. Hot, J. Karsenty, L. Kiakouama-Maleka, G. Lina, J. M. Maury, P. Miailhes, L. Moreau, P. Nesme, J. Ninet, L. Perard, T. Perpoint, E. Perrot, A. G. Ranc, JP. Rasigade, R. Reix, A. S. Renaud-Baron, J. Saison, A. Senechal, P. Sève, P. J. Souquet, H. van Thai, F. Tronc, F. Valour, P. Vanhems.

Disclosures. Zoé Cavalli, Florence Ader, Florent Valour, Julien Saison, Loïc Boussel, Oana Dumitrescu, Thomas Perpoint, Christian Chidiac, Thierry May, and Tristan Ferry declare that they have no conflicts of interest. 
Compliance with Ethics Guidelines. All procedures followed were in accordance with the ethical standards of the responsible committee on human experimentation (institutional and national) and with the Helsinki Declaration of 1964, as revised in 2013. Informed consent waiver was granted as all data were currently in existence.

Open Access. This article is distributed under the terms of the Creative Commons Attribution-NonCommercial 4.0 International License (http://creativecommons.org/licenses/ by-nc/4.0/), which permits any noncommercial use, distribution, and reproduction in any medium, provided you give appropriate credit to the original author(s) and the source, provide a link to the Creative Commons license, and indicate if changes were made.

\section{REFERENCES}

1. Peto HM, Pratt RH, Harrington TA, LoBue PA, Armstrong LR. Epidemiology of extrapulmonary tuberculosis in the United States, 1993-2006. Clin Infect Dis Off Publ Infect Dis Soc Am. 2009;49(9):1350-7.

2. Guirat A, Koubaa M, Mzali R, Abid B, Ellouz S, Affes $\mathrm{N}$, et al. Peritoneal tuberculosis. Clin Res Hepatol Gastroenterol. 2011;35(1):60-9.

3. Sanai FM, Bzeizi KI. Systematic review: tuberculous peritonitis-presenting features, diagnostic strategies and treatment. Aliment Pharmacol Ther. 2005;22(8):685-700.

4. Chow KM, Chow VCY, Hung LCT, Wong SM, Szeto CC. Tuberculous peritonitis-associated mortality is high among patients waiting for the results of mycobacterial cultures of ascitic fluid samples. Clin Infect Dis Off Publ Infect Dis Soc Am. 2002;35(4):409-13.

5. World Health Organization. Global tuberculosis report 2015. 2015. Disponible sur: http://apps. who.int/iris/bitstream/10665/191102/1/978924156 5059_eng.pdf?ua=1.

6. Kamerbeek J, Schouls L, Kolk A, van Agterveld M, van Soolingen D, Kuijper S, et al. Simultaneous detection and strain differentiation of Mycobacterium tuberculosis for diagnosis and epidemiology. J Clin Microbiol. 1997;35(4):907-14.

7. Brudey K, Driscoll JR, Rigouts L, Prodinger WM, Gori A, Al-Hajoj SA, et al. Mycobacterium tuberculosis complex genetic diversity: mining the fourth international spoligotyping database (SpolDB4) for classification, population genetics and epidemiology. BMC Microbiol. 2006;6:23.

8. Bhargava DK, Shriniwas, Chopra P, Nijhawan S, Dasarathy S, Kushwaha AK. Peritoneal tuberculosis: laparoscopic patterns and its diagnostic accuracy. Am J Gastroenterol. 1992;87(1):109-12.

9. Oge T, Ozalp SS, Yalcin OT, Kabukcuoglu S, Kebapci M, Arik D, et al. Peritoneal tuberculosis mimicking ovarian cancer. Eur J Obstet Gynecol Reprod Biol. 2012;162(1):105-8.

10. Chow KM, Chow VC-Y, Szeto CC. Indication for peritoneal biopsy in tuberculous peritonitis. Am J Surg. 2003;185(6):567-73.

11. Vardareli E, Kebapci M, Saricam T, Pasaoglu O, Açikalin M. Tuberculous peritonitis of the wet ascitic type: clinical features and diagnostic value of image-guided peritoneal biopsy. Dig Liver Dis Off J Italy Soc Gastroenterol Italy Assoc Study Liver. 2004;36(3):199-204.

12. Hong KD, Lee SI, Moon HY. Comparison between laparoscopy and noninvasive tests for the diagnosis of tuberculous peritonitis. World J Surg. 2011;35(11):2369-75.

13. Kong Y, Cave MD, Zhang L, Foxman B, Marrs CF, Bates $\mathrm{JH}$, et al. Association between Mycobacterium tuberculosis Beijing/W lineage strain infection and extrathoracic tuberculosis: insights from epidemiologic and clinical characterization of the three principal genetic groups of $M$. tuberculosis clinical isolates. J Clin Microbiol. 2007;45(2):409-14.

14. Svensson E, Millet J, Lindqvist A, Olsson M, Ridell $\mathrm{M}$, Rastogi $\mathrm{N}$, et al. Impact of immigration on tuberculosis epidemiology in a low-incidence country. Clin Microbiol Infect Off Publ Eur Soc Clin Microbiol Infect Dis. 2011;17(6):881-7. 